Article

\title{
The Role of Trust in Sustainable Management of Land, Fish, and Wildlife Populations in the Arctic
}

\author{
Jennifer I. Schmidt ${ }^{1, *(1)}$, Douglas Clark ${ }^{2}$, Nils Lokken ${ }^{2}$, Jessica Lankshear ${ }^{2}$ and Vera Hausner ${ }^{3}$ \\ 1 Institute of Social and Economic Research, University of Alaska Anchorage, 3211 Providence Drive, \\ Anchorage, AK 99508, USA \\ 2 School of Environment and Sustainability, University of Saskatchewan, Saskatoon, SK S7N 5C8, Canada; \\ d.clark@usask.ca (D.C.); nal.275@usask.ca (N.L.); Jessica.lankshear@rdc.ab.ca (J.L.) \\ 3 The Arctic Sustainability Lab, Department of Arctic and Marine Biology, UIT-The Arctic University of \\ Norway, The Arctic University of Norway, Framstredet 39, Biologibygget, N-9019 Tromsø, Norway; \\ vera.hausner@uit.no \\ * Correspondence: jischmidt@alaska.edu; Tel.: +1-907-786-5497
}

Received: 23 June 2018; Accepted: 27 August 2018; Published: 1 September 2018

\begin{abstract}
Sustainable resource management depends on support from the public and local stakeholders. Fish, wildlife, and land management in remote areas face the challenge of working across vast areas, often with limited resources, to monitor land use or the status of the fish-and-wildlife populations. Resource managers depend on local residents, often Indigenous, to gain information about environmental changes and harvest trends. Developing mutual trust is thus important for the transfer of knowledge and sustainable use of land resources. We interviewed residents of eight communities in Arctic Alaska and Canada and analyzed their trust in resource governance organizations using mixed-methods. Trust was much greater among Alaska (72\%) and Nunavut $(62 \%)$ residents than Churchill (23\%). Trust was highest for organizations that dealt with fish and wildlife issues, had no legal enforcement rights, and were associated with Indigenous peoples. Local organizations were trusted more than non-local in Alaska and Nunavut, but the opposite was true in Churchill. Association tests and modeling indicated that characteristics of organizations were significantly related to trust, whereas education was among the few individual-level characteristics that mattered for trust. Familiarity, communication, and education are crucial to improve, maintain, or foster trust for more effective management of natural resources in such remote communities.
\end{abstract}

Keywords: Arctic; climate; knowledge; governance; Indigenous; trust; wildlife; land; sustainability; management; natural resources

\section{Introduction}

Sustainable management of resource depends on a good working relationship between local stakeholders and resource governance institutions. Trust is central to successful working relationships between resource users and management agencies that yield both sustainable land use and desired ecosystem services [1-3]. Higher levels of trust have been associated with greater compliance [4], reduced conflict [5], and support for management plans [6-8]. Furthermore, trust can help facilitate more effective communication, improve collaborations, and settle issues through negotiation [9-11]. Developing trust is crucial for sharing information and developing rules that agree with local norms, which can support natural resource management in remote areas where monitoring and enforcement is difficult and expensive [12-14]. Overall, a good working relationship with resource users can help managers craft policies that better reflect the socio-ecological dynamics and the problems they seek to 
solve [15]. When trust is better understood, governance can be more effective, compliance improved, resources more sustainably used, and end users left more satisfied [14,16].

Trust is commonly defined as "the willingness to accept vulnerability, and in doing so participants involved believe that they will not take advantage of each other's vulnerabilities" $[17,18]$. The willingness to accept such vulnerabilities is related to events, both historic and recent, real and imaginary, that can meld trust and have ramifications for respect, communication, and power relationships between management agencies and resource users [19,20]. Personal history matters for trust in management agencies and could vary among individuals depending on socioeconomic characteristics such as age, sex, education, employment, ideology, previous experiences and their pre-disposition of trust to organizations and governments [21,22]. However, trust is not only about who is trusting, but also about who are trusted, such as the governing organizations that decide upon actions and regulations for managing fish, wildlife or land. Sharp, et al. [23] argued that to understand trust relationships between management agencies and community members, it is necessary to distinguish between the trusting intentions of the community members and the characteristics of agencies that make them trustworthy. Three characteristics are typically associated with the trustworthiness of governing organizations: ability (e.g., the agency has the appropriate knowledge, skills, or competency to manage fish-and-wildlife populations); benevolence (e.g., the belief that the management agencies act with the best interest of community members in mind), and, integrity (e.g., the management agencies are believed to act in accordance with a set of values and norms that is shared and accepted by community members) $[23,24]$. Some also argue that shared values should be a separate from integrity because they are formed over a longer period of time [25].

Trust depends on both the characteristics of community members and the characteristics of governing organizations, but the relative importance of such characteristics is cognizant of the local context [26]. For example, in Scandinavia, people put more trust in the government to solve collective challenges than many other countries [27], which could make individuals more willing to trust management agencies despite disagreeing about specific policies or management actions [28-30]. Interpersonal trust and personal experiences with managers could play a less significant role for trust in agencies when decision-making processes are considered fair and legitimate by the community. Culture and historical experiences could also matter for trust in management agencies [31]. For instance, in Suriname, small-scale gold miners have accumulated distrust of the government after re-occurring violations of cultural norms and codes of conduct associated with oral agreements [32]. Past experiences can cause individuals to base trust on ethnicity [31]. History helps shape culture and often this is done over numerous generations, so changes in trust based on ethnicity, culture, and historical events may be hard to alter.

In this paper, we examined to what extent individual-level socioeconomic characteristics, organizational-level characteristics, and contextual factors are determinants of trust in governing organizations in eight remote and predominantly Indigenous communities in the arctic regions of Alaska and Canada. We suggest a set of socioeconomic and organizational-level characteristics specific for Indigenous communities in remote and peripheral areas that we expect to be important for trusting relationships between local resource users and governing organizations. Socioeconomic characteristics that influence trust can be inherent such as age and gender or amendable like education, employment, and income [21,22]. Older individuals and those with lower levels of socioeconomic status (i.e., higher education, more income) are more likely to trust information or authority figures [21]. Meanwhile, organizations that share values with resource users are more likely to garner higher levels of trust. In remote Arctic communities, most residents depend on fish, wildlife, and access to land, so agencies that promote this should have higher levels of trust [7].

Contextually the regions included here differ with respect to the development of Indigenous rights in decision-making which is likely to influence trust relationships between resource users (i.e., trustor) and governance organizations at different levels (i.e., trustees). Higher degree of local Indigenous inclusion in Nunavut compared with Alaska is likely to influence trust in governmental organizations. 
Land settlement histories and governance regimes vary significantly between and within these regions. The trust that local resource users have in authorities are strongly influenced by the recent history of Indigenous-state relationships, which have greatly influenced the power structure and legal rights afforded to their respective residents [33]. The Inuit population in Nunavut, in particular, has more formal rights in resource governance through the Nunavut Land Claims Agreement (NLCA) and the multilevel co-management system built around principles of Inuit Qaujimajatuqangit (IQ) [34]. Indigenous rights in Alaska were first settled through the U.S. government's Alaska Native Claims Settlement Act (ANSCA) in 1971. ANSCA resulted in no legal mandates providing differential access to natural resources or requirement to specifically include Indigenous residents in management.

Another contextual factor that can influence trust is remoteness, which can influence the ability of rural residents to interact directly with management personnel. Trust may be more influenced by images of agencies through, media, reputation or regulatory procedures [7]. In the absence of interactions between government agencies and individuals, individuals can form trust based on a person's title or level of authority [26]. For Indigenous people, historical events might lead to a predisposition to not trust government-based agencies [35]. Churchill, on the other hand, is less remote, but residents there are highly influenced by a legacy of decisions made by large external corporations [36]. The predisposition to trust agencies could depend both on Indigenous populations' sociocultural context as well as their experience and influence in fish, wildlife, and land management in the three regions.

Beyond formal participation in governance, culture and cultural norms greatly influence inherent trust. Within Inuit communities, strong sharing networks (i.e., food, equipment, etc.) require a certain level of trust and acceptance of vulnerability because resources can come and go, and one day that same individual or family may be without supplies. This extends not only to immediate family members, but also to unrelated community members [22,37]. These sharing networks imply a certain level of trust among community members and illustrate how trust can be a two-way street because there is the understanding that by giving you are more likely to receive.

Our research is novel because trust relationships between local resource users and governing agencies have not previously been examined across countries in the Arctic. Most cross-national or cross-cultural comparisons, such the World Value Surveys, do not include the northernmost sub-regions $[38,39]$. We suggest and explore characteristics of governing organizations and management agencies that could potentially be determinants of trust in remote areas were Indigenous people reside. To allow for comparison while exploring the sociocultural context of trust relationships, we used mixed-methods interviews yielding comparable qualitative and quantitative datasets to address questions about trust and relationships between residents and organizations across different Arctic regions [25].

\section{Research Aims and Objectives}

Trust has a different meaning in the research literature depending on disciplines and the context in which the concept is used [40]. In the natural resource management literature, the focus has largely been on trust relationships between community members and governmental agencies in specific cases $[14,40]$. Trust in governmental agencies and organizations can be based on interpersonal trust (i.e., trust in people) through interactions with public officials. Trust is also formed through agreement on the general principles and norms for resource governance (i.e., institutional trust). Sharp, Thwaites, Curtis and Millar [23] distinguish between the trusting intentions of community members (i.e., the trustors) and the trustworthiness of the organization or management agency being trusted (i.e., the trustees). In the context of natural resource governance, trust relationships depend on: the resource users, the characteristics of the organization or management agency that govern resource users, as well the local context in which these relationships are formed [14,40,41]. As most trust research in natural resource management has targeted specific management challenges and governmental agencies $[6,42,43]$, there is limited research on whether trust is lower or higher, depending on the 
multiple characteristics and scale of organizations involved in resource governance (e.g., wildlife agencies, Indigenous governance organizations, local politicians).

Due to the remoteness of these communities, we expect that personal interactions with managers could be important, and therefore it is likely that scale matters for trust relationships (i.e., resource users will be more inclined to trust local organizations over non-local ones). We also expect organizations that are likely to share values and norms with local residents will be more trustworthy than organizations less familiar to people. We therefore assessed whether residents have higher trust in Indigenous, non-formal and fish-and-wildlife organizations than others. Non-formal is defined as agencies that do not have legal authority to enforce rules and regulations and administer citations. Trust in the knowledge, skills and competencies to manage fish-and-wildlife populations could also influence compliance to management decisions.

Resource governance (i.e., the local context) differs substantially regarding Indigenous rights in decision-making throughout the Arctic, which may influence trust relationships between resource users and governance organizations at different levels. Consequently, our paper aims to examine these three elements of trust (individual-level characteristics, organizational-level characteristics and local context) in an integrated fashion. We ask:

1. What characterizes the organizations or management agencies that are trusted or distrusted among the resource users?

2. How does trust in organizations and management agencies vary depending on individual-level socioeconomic characteristics?

3. How does the local context of regions and communities (i.e., histories, governance, sociocultural environments, etc.) result in different levels of trust between the trustor and the trustees?

To answer the questions above, we conducted interviews in eight communities-four in Alaska, three in Nunavut, and one in Manitoba-to assess their trust in governance institutions that influence local resource management and who they trust for knowledge about fish and game populations they harvest. We used mixed-methods interviews to analyze heterogeneity in trust levels in relation to sociocultural characteristics in the three regions. Basic statistical methods were used to analyze trust levels and our results were combined with literature and the participants' own reflections to explain the differences between regions and processes leading to differences in trust in governing organizations within communities. Since there are limited previous studies on trust relationships in the Arctic, we combine the assessment of level of trust in different organizations with letting participants reflect on why they trust these organizations or not.

\section{Materials and Methods}

\subsection{Interview Design and Methodology}

We designed a mixed-method interview protocol that allowed us to combine the quantitative instruments to measure degree of trust depending on characteristics with trustors, trustees, and the local context, with open-ended questions allowing interpretation of trust relationships in the communities. Frels and Onwuegbuzie [44] argued that mixed-method interviews improve rigor in the data collection process by using quantitative instruments integrated with qualitative open-ended questions. Our analysis is focused on the trust scale for organizations (i.e., trustees) that we developed together with a research team working together in the circumpolar region (Alaska, Canada, Norway and Russia). For cross-cultural comparison on this scale, we needed quantitative instruments to analyze the heterogeneity among trustors (i.e., individual-level characteristics) and trustees (characteristics with organizations and agencies). While this quantitative instrument is our primary research target in this paper, we have also included open-ended questions from the interviews to bring in the participants' insights on why the organizations are trusted or not (see Supplementary Material; Table S1). While the mixed-method analysis presented here was dominated by quantitative approaches, we stressed the 
need to remain sensitive to the sociocultural context we are working in and let the local perspectives also emerge through interviews. We therefore combine the quantitative analysis of the trust with qualitative approaches.

We did a prior screening to identify the specific organizations that were relevant for each community ( $n=34$; Table S2). For example, organizations associated with wildlife, fish, and land issues were included, since subsistence is important. Local organizations and government were included, because their actions could directly affect local residents. Organizations varied and included: scale (i.e., local, sub-national, and national), Indigenous in nature (i.e., primarily employed or run by Indigenous peoples), elected by the public (i.e., whether the leaders of the organization were elected by the public), fish-and-wildlife based industry (i.e., mining, oil, and gas), and lastly if the organization has legal authority (e.g., are able to issue citations or assign criminal penalties). Local organizations were those that operate and are managed by residents within the community. In Alaska, all organizations $(n=12)$ were asked about in each of the four communities, except for the city council in Noatak because it does not have a formally organized municipal government. The only overlapping organization between Canada regions, Nunavut and Churchill, Manitoba, was the federal government (i.e., national scale). A few more organizations were assessed during the interviews in Manitoba $(n=13)$ versus Nunavut $(n=10)$. We did not include results from organizations involved or related to resource extraction in the modeling because there were only a couple and our focus was on fish, wildlife, and conservation. However, since the organizations have a different mission and perspectives on fish and wildlife, inclusion of the results helps illustrate the influence of organizational characteristics.

Similar to other large-scale surveys (see [25]), trust was assessed by simply asking people to report how much trust they have in these specific organizations without defining trust or specifying which kind of trust construct we based our study on. The participants were asked to rate their trust in the listed organizations and add organizations that were important to them, but not on the list. Answers were originally collected on a scale of one to seven, with seven representing the greatest trust and one the least. To ensure consistency among participants, we used a laminated card that described the different levels of trust. We also asked about the trust in information sources about fish-and-wildlife populations to assess whether the agencies were perceived as having the appropriate knowledge, skills, or competencies to manage fish-and-wildlife populations. Since our purpose was to assess and compare trust in organizations across the Arctic, we had to construct the questions as simple as possible and examine their reason for scoring different organizations higher than others through open-ended questions.

Among the regions, natural resource management agencies often have similar missions and collect similar data, which helped to reduce the variability in what is being used to assess trust. In addition, we used the comments regarding trust during interviews to provide insight into how interviewees perceived and assessed trust; no large discrepancies were noted. Given the relatively few responses for two and six (1.8\%), we categorized the data into yes (5-7), partly (4), and no (1-3). If participants for different reasons did not want to use the scale, we let them answer yes, no or partly. Participants were also asked to identify the two most important organizations, and to explain why these organizations are influencing their use. We totaled up the number of times an organization was mentioned as important and calculated the percent of the responses for each organization.

\subsection{Quota Sampling and Recruitment}

Interviews took place during the winter and summer of 2013 (Figure 1; Alaska, $n=64$; Churchill, $n=17$, Nunavut, $n=50$ ). We chose communities that were based in the Arctic, half of which have nearby natural resource extraction activities (e.g., mining, oil/gas) or infrastructure associated with such activities. Atqasuk is on the North Slope of Alaska with oil and gas activities and Noatak is near the Red Dog Mine, which employs local residents [45]. In Canada, Baker Lake is near the Meadowbank mine and Churchill had a deep-sea port (closed in 2016) and railroad (washed out in 2017). While specific results are necessarily dependent on the eight communities selected, taken together, these 
communities have socioeconomic and cultural characteristics (i.e., size, ethnicity, mixed-economies, harvesting patterns) typical for their respective regions [46-49]. Prior to the interviews, we conducted preliminary fieldwork, which involved contacting members of the communities, meeting with community organizations, and gaining their approval for our research [50]. This research was reviewed and approved by the Institutional Review Board (\# 331947) in Alaska and ethical approval for the research was also granted by the University of Saskatchewan Behavioural Research Ethics Board (protocol \# BEH 13-129), and the Nunavut Research Institute (\# 03009 13N-A). Quota sampling was used as a flexible approach to select participants to ensure heterogeneity in our sample. Subsistence activities may differ based on gender and age [22,37] and trust in governance may be influenced by familiarity or experience [51]. We, therefore, used gender, age and leader role as the three main criteria for ensuring heterogeneity. With the help of local individuals and the local Hunters and Trappers Organizations (HTO) in Nunavut, we chose 16 people highly engaged or highly knowledgeable about subsistence activities with an attempt to include an equal number men and women, elders ( $>55$ years old) and youth (18-54 years old), and half of the individuals involved in government (e.g., city or tribal council, school board, wildlife boards, etc.). See Table S3 for a more detailed description of the individuals interviewed. In Alaska, a local resident helped to select people, in Nunavut the local HTO helped to select people, and in Churchill, the interviewer resided in the community. English was the primary language used during the interviews, but when necessary we used a local translator.

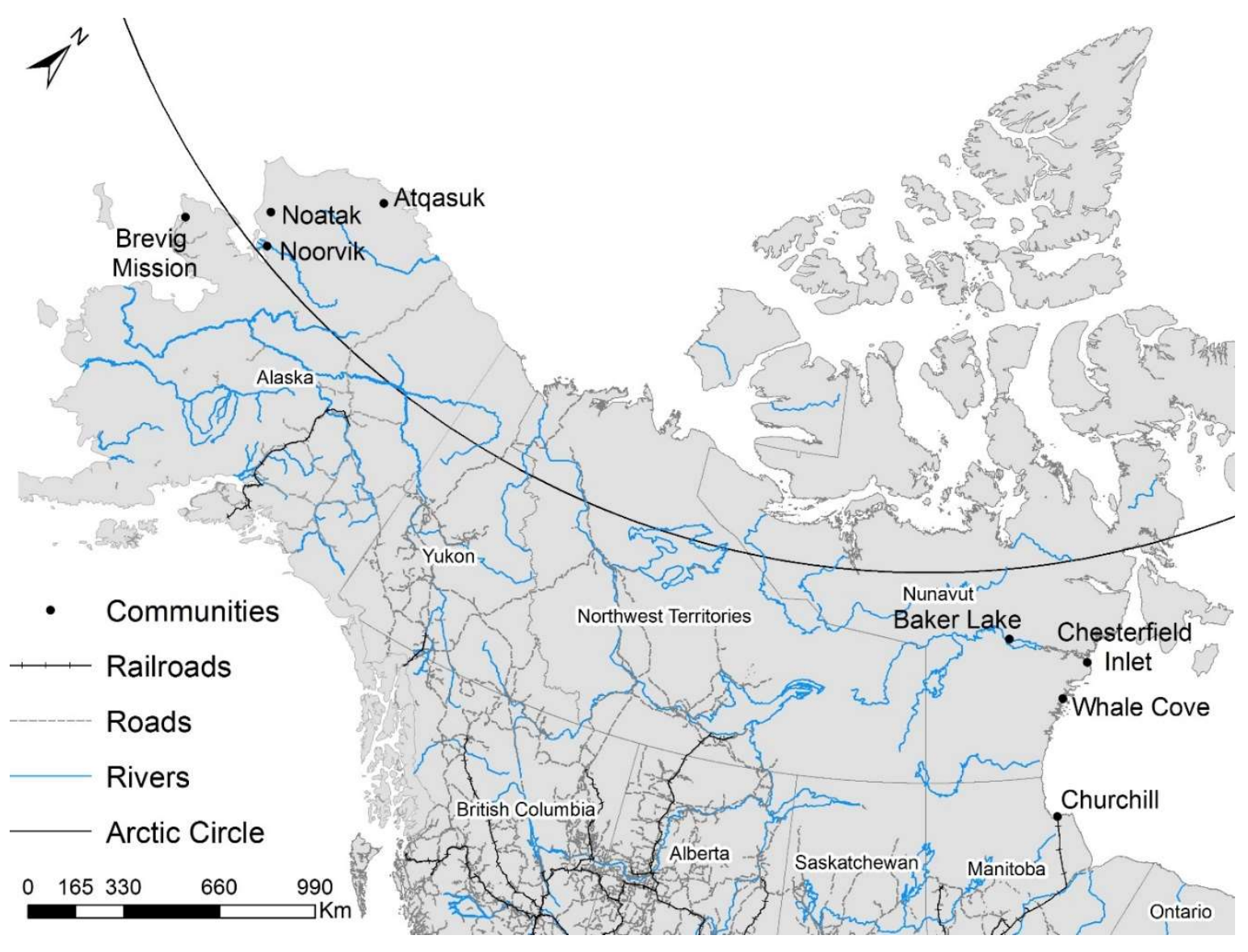

Figure 1. Locations of communities interviewed in Alaska, Manitoba, and Nunavut.

\subsection{Data Analysis}

We used descriptive statistics to examine the data and interactions that were not feasible to include in the model due to low sample sizes $(n<3)$. Within each region, if a category with a parameter contained less than three observations, the number of categories within the parameter were reduced. 
This was done for marital status, education, and residency. Marital status was collapsed into single (e.g., divorced, widow, and separated) or other (e.g., married and partner). Education was classified as high school, secondary or some secondary, and post-secondary (i.e., graduate school). Residency was classified as 30 years and over in the community or under. The newly classified parameters were examined again for sample size and correlation with other parameters. To test for correlations, we used Chi-square for two-way comparisons and Cochran-Mantel-Haenszel (CMH) for multiple comparisons [52]. These tests were also used to assess whether differences in trust occurred between various characteristics of interviewees or organizations. Since the organizations differed among regions, we also calculated $\mathrm{CMH}$ with and without controlling for region and parameters that were significantly correlated $(p<0.05)$ with trust included in our model. Since organizations focused on industrial activities are unique and dependent on outside influences, we analyzed this group of organizations independent of all other analyzes and they were not included in modeling. Stepwise regression (15\% to enter the model and $10 \%$ to stay in the model) with a cumulative logit link function was used to determine which of these parameters should be included in a final model. To avoid overfitting, the remaining parameters chosen by the stepwise regression process were individually dropped and if the increase in AICc scores was minimal $(<2)$ we removed them, otherwise they remained in the model $\left(\mathrm{SAS}^{\circledR}[53]\right.$ ). During our examination of models, our results indicated that region violated the proportional odds assumption, which is known to be overly sensitive especially when cell counts are small [54]. We ran the model with and without region as a nominal effect and results were slightly different, but the significance (e.g., $p$-value) did not change, so we proceeded with only interviewee as a random effect [55]. Interviewee was a random effect because each person was asked about trust in multiple organizations. The final ordered logistic model equation ([56]; Stata method = mvaghermite) to predict the probability of a given trust level is given in Equation (1). Interviewee was included as a random effect because individuals tend to respond differently to questions in ways that are not relevant to the research question [57]. We also ran the model without interviewees as a random effect to determine the influence of correlation among answers within individuals. All models were run using SAS and Stata.

$$
\text { Probability of a given trust level }=\lambda_{i j c}=\alpha_{c}+\beta_{j} x_{j}+\gamma_{i} z_{i}+\mu_{i}+\varepsilon_{i j}
$$

$c=$ No, Partly, Yes, levels of trust; $i=1, \ldots n$, individual $j=1, \ldots n$, organization; $\alpha_{c}=$ threshold for trust levels; $\beta_{j}=$ organization coefficient; $\gamma_{i}=$ individual coefficient; $\mu_{i}=$ random effect error; $\varepsilon_{i j}=$ random effect logistically distributed.

In addition to the quantitative analysis, we also examined the comments throughout the interview that addressed much more than the numerical trust scores and included a deeper reflection by participants about the trust relationships between governance organizations and resource users. Even though we used all interview questions to draw conclusions on trust, there were a few questions that were very informative. These include: "Where do you get your information about animal numbers and locations?" and "Which sources do you trust or not trust regarding information about resource abundance?" We totaled up the comments that mentioned trust and coded these according to their expressed trust (i.e., positive, negative, or neutral). Thereafter, we analyzed the data qualitatively- by studying the common themes and statements relevant for evaluating the trustworthiness of the organizations (i.e., ability, benevolence and integrity/values) — to identify explanations for their trust assessment. We noticed that many of the organizations that impact fish, wildlife and land management in the Arctic was not familiar to the participants. Since familiarity with organizations can influence trust, we used linear regression to examine the association between the percent of interviewees who responded "don't $k n o w$ " for an organization versus the percent that indicated that they trusted an organization within each region. Our qualitative data also complement the results from the quantitative analysis of the trust scores and provide insights into why participants assessed some organizations as being more trustworthy than others. 


\section{Results}

There was a significant association between trust and characteristics of individuals (Table 1). Where the resident lived varied significantly by location, when characteristics of interviewees and organizations were not taken into consideration (Table 1). Alaska expressed much more trust, Nunavut slightly less, and Churchill had low levels of trust (Table 1). Marital status $(p=0.04)$ and gender ( $p$ $=0.03$ ) were also associated with trust shown by married females, illustrating higher levels of trust. Even though individuals with higher education tended to have higher levels of trust, this relationship was not significant (Table 1). Only half of the individual characteristics were significantly associated with trust, but all the organizational characteristics were strongly associated (Table 1). Organizations that were associated with industry like mining or oil and gas or had legal enforcement powers, had significantly lower trust than those not associated with industry or legal enforcement (Table 1). Other organizational characteristics associated with trust were scale, whether the organization was involved in fish and wildlife management, or Indigenous status. Local organizations, those with Indigenous underpinnings, and those associated with fish and wildlife management had higher levels of trust (Table 1).

Table 1. Trust responses (\%) based on characteristics of interviewees and organizations with total number of responses. Results from either Pearson's chi-square test for individual characteristics and Cochran-Mantel-Haenszel test for organization to control for region.

\begin{tabular}{|c|c|c|c|c|c|c|}
\hline Individual & Parameter & Yes & Partly & No & $N$ & $p$-Value \\
\hline \multicolumn{7}{|l|}{ Region } \\
\hline & Alaska & 72.0 & 18.6 & 9.4 & 435 & \multirow[t]{3}{*}{$<0.0001$} \\
\hline & Churchill & 22.8 & 12.7 & 64.6 & 158 & \\
\hline & Nunavut & 62.2 & 16.8 & 21.0 & 434 & \\
\hline \multicolumn{7}{|l|}{ Education } \\
\hline & Less than secondary & 56.7 & 18.2 & 25.2 & 330 & \multirow[t]{3}{*}{0.271} \\
\hline & Secondary & 60.4 & 17.9 & 21.7 & 553 & \\
\hline & Post-secondary & 68.1 & 10.4 & 21.5 & 144 & \\
\hline \multirow[t]{3}{*}{ Residency } & & & & & & \multirow[t]{3}{*}{0.656} \\
\hline & Less than 30 years & 60.5 & 18.4 & 21.1 & 261 & \\
\hline & More than 29 years & 60.2 & 16.4 & 23.4 & 766 & \\
\hline \multirow[t]{3}{*}{ Marital } & & & & & & \multirow[t]{3}{*}{0.043} \\
\hline & Single & 56.6 & 18.0 & 25.5 & 412 & \\
\hline & Not single & 62.8 & 16.3 & 21.0 & 615 & \\
\hline \multicolumn{7}{|l|}{ Gender } \\
\hline & Male & 58.0 & 17.2 & 24.8 & 715 & \multirow[t]{2}{*}{0.032} \\
\hline & Female & 65.4 & 16.3 & 18.3 & 312 & \\
\hline \multicolumn{7}{|l|}{ Age } \\
\hline & Youth & 61.4 & 18.0 & 20.6 & 583 & \multirow[t]{2}{*}{0.130} \\
\hline & Elder & 58.8 & 15.5 & 25.7 & 444 & \\
\hline \multicolumn{7}{|l|}{ Organization } \\
\hline \multicolumn{7}{|l|}{ Scale } \\
\hline & Local & 66.7 & 13.7 & 19.6 & 255 & \multirow[t]{3}{*}{$<0.001$} \\
\hline & Sub-National & 65.9 & 17.9 & 16.2 & 536 & \\
\hline & National & 40.7 & 18.2 & 41.1 & 236 & \\
\hline \multicolumn{7}{|c|}{ Fish and wildlife } \\
\hline & Yes & 64.9 & 17.6 & 17.6 & 478 & \multirow[t]{2}{*}{$<0.001$} \\
\hline & No & 56.3 & 16.4 & 27.3 & 549 & \\
\hline
\end{tabular}


Table 1. Cont.

\begin{tabular}{lcccccc}
\hline Individual & Parameter & Yes & Partly & No & $N$ & $p$-Value \\
\hline Industry & & & & & & \\
\hline & Yes & 19.5 & 28.0 & 52.5 & 173 & $<0.0001$ \\
& No & 60.3 & 23.3 & 16.35 & 1101 & \\
\hline Legal authority & & & & & & \\
\hline & Yes & 45.7 & 18.7 & 35.6 & 438 & $<0.0001$ \\
& No & 71.1 & 15.6 & 13.2 & 589 & \\
\hline Indigenous * & & & & & & \\
\hline & Yes & 72.8 & 14.3 & 12.9 & 481 & $<0.001$ \\
& No & 49.3 & 19.2 & 31.5 & 546 & \\
\hline
\end{tabular}

* Only for Alaska and Nunavut.

Underlying differences with Churchill can get obscured because trust was so low and the sample size for Churchill is much smaller than Alaska and Nunavut (Table 1). However, the pattern of trust differed among the regions, with the trust of local organizations relative to larger scale organizations much lower in Churchill than in the other regions (Figure 2; Chi-Square 78.5, $\mathrm{df}=1, p<0.01$ ). Conversely, individuals from Alaska trusted local organizations more than those that were more distant (i.e., unfamiliar; $\beta=-0.89, \mathrm{df}=11, p<0.01$ ), while the same relationship occurred in Nunavut, though statistically insignificant (Figure 2). Similarly, there was a negative relationship between the percentage of people who said "don't know" for a given organization and the percent of people who said "they trusted" an organization in Alaska $\left(R^{2}=0.85, p<0.01\right)$; it was marginal in Nunavut $\left(R^{2}=0.22, p=0.05\right)$, and none in Churchill. The propensity to trust local organizations is likely tied to the greater portion of local organizations that were Indigenous $(45.5 \%)$, with the percentage decreasing as organizations became larger (subnational $=31.3 \%$ and National $=18.2 \%$ ). In addition, legal authority was not important for trust in Churchill (Chi-Square 2.0, $\mathrm{df}=2, p=0.36$ ), but was for Alaska and Nunavut (Chi-Square 11.2, $\mathrm{df}=2, p<0.01$; Chi-Square 31.0, $\mathrm{df}=2, p<0.01$ ). Furthermore, trust in legal authorities was opposite in Alaska and Nunavut in that trust was lower for organizations with legal authority, $65.2 \%$ vs. $79.1 \%$ and $44.4 \%$ vs. $70.2 \%$, respectively.

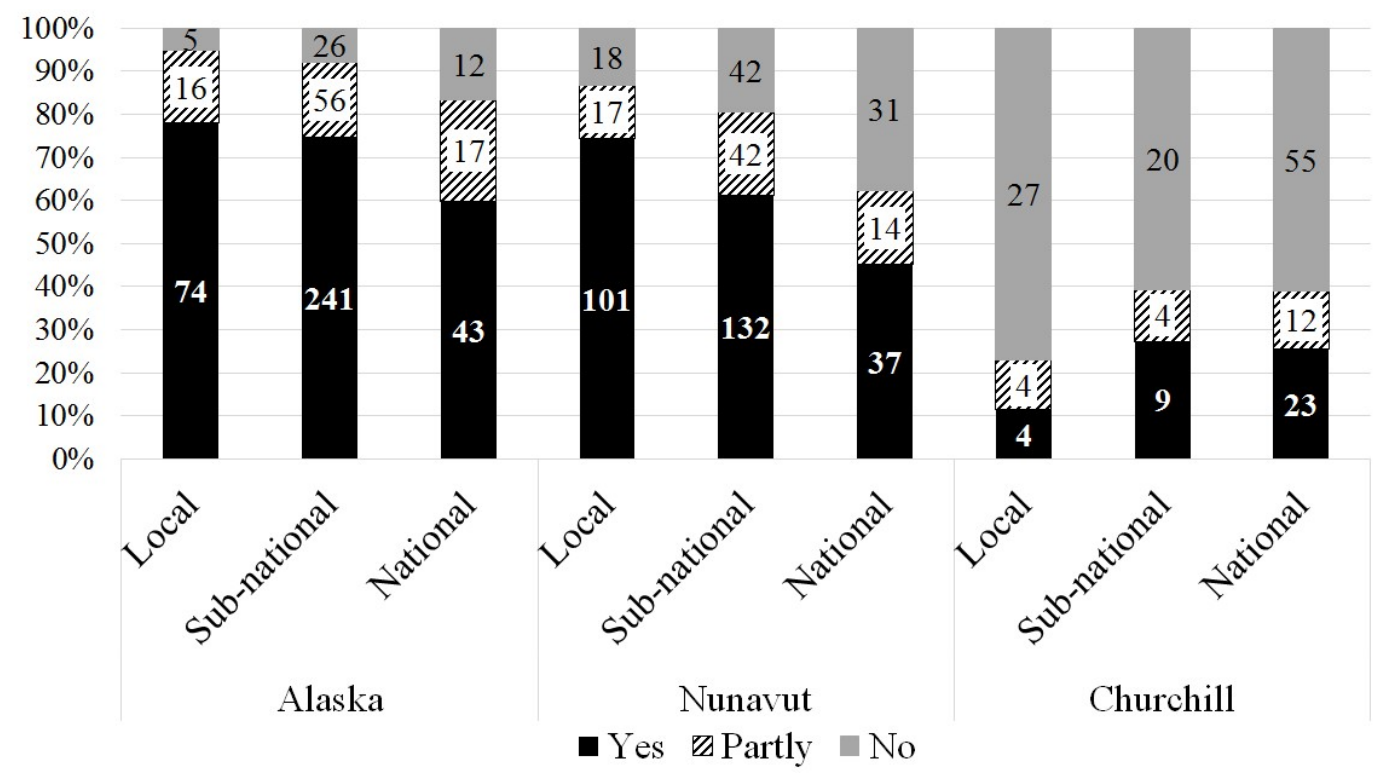

Figure 2. Trust frequency based on scale and region from interviews conducted in 2013. Number indicates sample size. 
The model with the lowest AIC score $(1722, \mathrm{df}=118)$ identified five variables to be significantly associated with trust, three of which represented characteristics of organizations: whether the organization was involved in fish and wildlife management or not $(p<0.01)$, scale of the organization $(p<0.01)$, and legal status of the organization $(p<0.01)$ and the other two represented characteristics of the interviewee-education level of the interviewee $(p<0.05)$ and residency $(p<0.01)$. Holding all other factors equal, respondents were $57 \%$ more likely to trust an organization whose purpose involved fish and wildlife management than one not involved in fish and wildlife. Trust was 47\% lower for organizations that had legal authority versus those that did not (Table 2). As organizations became larger in scale, trust decreased by $11 \%$. Churchill residents were $6 \%$ as likely to trust a given type of organization as an Alaskan counterpart, but this comparison was non-significant likely due to limited power (Table 2). Increased levels of education improved rates of trust towards agencies (Table 2). When the random effects of individuals were removed, the effect of region became more slightly more important and the influence of education decreased, but significance did not change.

Lastly, local organizations were identified as the most important by residents of Alaska (56\%) and Nunavut (46\%). These included local tribal (39\%) and city councils (26\%) in Alaska and HTOs (17\%) and hamlets (16\%) in Nunavut. In Churchill, the Hudson Bay Railway (21\%), Manitoba Hydro (14\%), and the port (14\%) were the most important.

Table 2. Ordinal regression model results with odds of trusting (e.g., yes rather than partly or no) organizations relative to the reference characteristic. For example, the odds of trusting in Churchill relative to Alaska. Values less than 1 indicate that you trust the left item (e.g., Churchill) is less than the right (e.g., Alaska).

\begin{tabular}{lcccc}
\hline Effect & Odds Ratio & Confidence Intervals & $p>|z|$ \\
\hline Location & & & & \\
\hline Churchill vs. Alaska & 0.06 & 1.58 & 0 & 0.09 \\
$\quad$ Nunavut vs. Alaska & 0.45 & 1.09 & 0.19 & 0.08 \\
\hline Scale & & & & \\
\hline$\quad$ National vs. local & 0.55 & 0.84 & 0.35 & 0.01 \\
$\quad$ Subnational vs. local & 0.66 & 0.96 & 0.46 & 0.03 \\
\hline Fish and wildlife & & & & \\
\hline$\quad$ Yes vs. No & 1.57 & 2.14 & 1.16 & \\
\hline Legal $\quad$ & & & \\
\hline$\quad$ Yes vs. No & 0.47 & 0.66 & 0.33 & 0 \\
\hline Education & & & & \\
\hline$\quad$ Secondary vs. less than secondary & 1.76 & 2.94 & 1.76 & 0.03 \\
$\quad$ Post-secondary vs. less than secondary & 2.61 & 5.20 & 1.05 & 0.01 \\
\hline
\end{tabular}

\section{Qualitative Analysis of Interview Data}

There were 83 comments made about who people trust for information about wildlife. The comments on trust were not straightforward to code according to the elements usually informing trust in organizations (i.e., ability, benevolence, and integrity) because this would have added an additional level of interpretation on the part of the researcher. Most of the trust assessments by our participants were related to the knowledge, skills and competencies that the agencies have, that is relevant for them. These included familiarity with the organization, communication, or direct interactions with managers.

Several of the participants mentioned the ability to communicate with managers or the desire to be informed as an explanation for their trust assessment. An interviewee in Baker Lake responded (through a translator), "He does not trust international governments or organizations, and partly trusts the KWB (Kivalliq regional wildlife management board), Government of Nunavut and Federal Government 
and HTO because he doesn't really hear from them." Many people in both Alaska and Canada mentioned the importance of communication in developing trust with managers or agencies. An interviewee in Chesterfield Inlet said (through a translator), "If he doesn't hear from them [manager], they are not reliable." Another resident in Whale Cove states (through a translator), "She hasn't gotten feedback from the wildlife biologists, so don't trust them." However, in the Northwest Arctic Borough where there has been a caribou working group and special control use areas due to user conflicts, residents in both communities mentioned, "The state keeps us informed. When the season is closed they let us know and where to hunt. Pretty good, nothing really bad."

Some participants also indicated that direct contact with organizations and familiarity matters. For, example people in Nunavut and Alaska often told us that they trusted HTOs and tribal and city councils the most because they are local. People also tended to trust local organizations or individuals regarding information about animal population numbers and locations. In addition, the comments shed some light about how people assess trust. For example, another interviewee in Baker Lake said (through a translator), "He can tell just by looking at a person whether he trusts them or not." While another person believes, "Where the respondent partly finds people reliable, he says it depends on how much you know them."

While more information and communication with management agencies were emphasized by some, there were some contradictory statements in some of the most remote communities in Alaska. Many people were unfamiliar with the organizations that are involved in the governance of fish, wildlife, and land resources. When asked about people representing the agencies, they often assumed the people doing their job were doing it well because they had seen animals around. When asked about management of caribou, an Atqasuk resident stated, "They keep the population up — must be doing a good job" and in Brevig Mission, "Moose are managed good because we hunt them when we see them." In Alaska, residents of Noorvik indicated that media (e.g., television, radio, and newsletters) was effectively used to distribute information about a caribou herd important to residents and its management. A resident stated, "When I see it on TV it sounds like they are doing a good job. But I am not sure what they do." Another stated, "State lets us know when to get caribou and how many. Gets information from the radio. Hunting regulation book picked up from the post office." Overall, these statements show that many of the resource users did not have direct contact with the organizations that make decisions about management, and trust was therefore assessed by when they heard in the media or by the performance in terms of the status of fish-and-wildlife populations.

People also talked about aspects of the resource when talking about trust, indicating that management do not really matter for fish-and-wildlife populations. For example, several of the comments expressed the highly unpredictable nature of caribou. A common comment from these areas was "... it depends on mother nature [if animals increase]". People in Alaska and Nunavut commented on mother nature and the presence of cycles that people may not influence. "Everything is a cycle. I would say leave it to mother nature. Population size comes and goes. It is nature." Even though the term 'mother nature' was not used in Nunavut, the same sentiment is expressed. For example, when asked about reasons for changes in caribou abundance, several residents responded, "No special reason it is natural."

Other issues that were mentioned either directly or indirectly during interviews about trust were ethnicity, age of the person (i.e., elder-versus youth), and the amount of expertise the person or people in an agency possessed. In Whale Cove, an interviewee stated (through a translator), "He trusts elders and hunters more than biologists." Some people mentioned that they were not talking to non-Indigenous people much. In Alaska, the length of employment by a local area biologist was mentioned as important for trust and relationships. In addition to long-term employment, one way to express expertise and gain trust, especially as resource managers and scientists, is to spend time in the field and with local residents, as indicated by comments such as this: "Does not trust scientists who only go out for a few days. They should stay in the field for a year or more, not a week" or "scientists don't spend enough time in the north to do their research." This is especially important in the Arctic, which has seen an 
increase in interest by the scientific community and limited funds can result in abbreviated time spent in communities.

\section{Discussion}

We found organizational-level characteristics to be important for trust assessment in the Arctic communities. Residents participating in our study generally reported higher trust in local and non-formal organizations whose main purpose was fish-and-wildlife management. Among the individual-level socioeconomic characteristics, only education was selected in the final model. It is also notable that the regional difference found in the association tests did not have a significant influence on trust during modeling when the organizational-and the individual level characteristics were accounted for. Participants that assessed organizations negatively explained their trust relationship by the lack of direct contact with management agencies, information, and poor communication with resource users. We also noticed that when many of the local resource users that were not personally familiar with the organizations in question, they based assessments using media, reputation or how fish-and-wildlife populations are performing, reported, or regulated. Below, we summarize results from our three initial questions and what they mean for fish, wildlife, and land management and sustainable use of natural resources.

\subsection{Trust and Characteristics of Organizations}

The high trust in local and non-formal organizations is not surprising provided the remoteness of the communities assessed in our study. Local agencies benefit from daily interactions, awareness of pressing needs, and have the opportunity to give direct feedback to local resources through local meetings [58-60]. Employing long-term local or regional residents who can work with the community plays a big role in fostering or maintaining trust in fish and wildlife management [61,62]. The familiarity and trust with local management agencies or employees who stay long-term in the communities also relates to perceptions of knowledge, skills, and competency important for managing the resources. If people think that an organization is competent, they are more likely to trust it [63].

As indicated in our study, lower levels of trust were generally associated with poor communication with users. A review of co-management groups in the fisheries section found that even with stakeholder involvement, trust can be improved by better exchange of information between users and managers [64]. The importance of communication and transparency emphasized by the interviewees could be important for sustainable management of resources, as people that are "kept in the loop" and listened to are more likely to trust the information and decisions of management agencies $[16,65,66]$. However, the lower level of trust in organizations with legal responsibility for managing fish, wildlife, and land could also be the perceived salience of western science in informing about fish-and-wildlife populations. Many of the respondents who reported lower levels of trust in formal organizations explained that populations do not need to be managed, as nature decide their fluctuations. The understanding of resources as determined by nature and by the respect for the animals as code-of-conduct is an important part of the Inuit culture [67] and could explain why some participants have lower trust in formal organizations that are required to abide by legal mandates. Organizations that are non-formal are likely to share the local norms, values and knowledge, and are thereby considered as having a higher integrity among the Inuit populations. Lack of respect of local norms and code-of-conduct, particularly relating to non-formal oral agreements, was also identified as a determinant of trust in the Suriname case [32].

The lack of familiarity of the organizations that are managing resources was also evident in some of these remote communities and has some implications for the trust assessment of management agencies. When there is a low level of contact with external organizations, trust could be assessed by the title of the organization, through images produced in the media, reputation, formal regulations [7], or as emphasized by our participants, also the status of the fish-and-wildlife populations. Fish and 
wildlife organizations and Indigenous organizations could be assessed by participants by their names rather than direct experience with their managements.

\subsection{Trust and Characteristics of Individual Resource Users}

The modeling indicated that higher education was positively associated with trust, which has also been found in other research [68-72]. Overall, the pursuit of education may indicate that a person is more prone to understand the agencies' rationale, more open to trusting what an organization tells them, and may be better at understanding or acknowledging unknowns in complex natural systems $[68,71,72]$. Fish, wildlife, and land managers can show interest in learning by engaging youth in management and scientific inquiry, which eventually can increase trust between users and management agencies [73]. This is exemplified by two of our communities in Alaska, where a long-term area biologist (30 years) actively participated in kids' day which is an event that facilitates learning among the youth about local fish and game. In addition, like Hooghe, Marien and de Vroome [68] we also believe that there are secondary effects of having a higher education that help foster positive relationships. In rural Alaska and Canada, residents often move outside of their communities to receive higher education and if they move back, they are often sought after to serve on board(s) within a community and thus be more familiar with agencies.

There were some indications that single males assessed organizations more negatively than married females (Table 1), but these characteristics were not identified as an influential determinant in our model (Table 2), and the reasons for such a pattern were not evident from our qualitative analysis.

\subsection{Context and Trust Relationships between the Trustor and the Trustees}

While organizational-level characteristics could influence some broad patterns of trust as discussed above, trust depends also on previous experiences with management agencies [32]. In our case, Churchill deviates from the pattern described above and provides an example of where lack of communication, uncertainty, and a sense of insecurity can overcome the significance of having a local presence; all three of which are associated with lower trust [74,75]. Local residents have perceived decisions being made by local agencies and corporations as not being in their best interests, and have negative experiences with ongoing, long-term decision processes that relate to the railway and the port $[36,76]$. In the past, the Churchill River was also diverted upstream for hydroelectric power generation, severely impacting entire First Nations and other regional residents, who were not compensated for potential loss of hunting grounds [77].

The higher trust in Alaska of fish and wildlife management is consistent with other research that determined that Alaska had the highest satisfaction with resource management $(18 \%)$ versus Greenland $(3 \%)$ and Chukotka (2\%); Canada was not surveyed [78]. The Survey of Arctic Living Conditions (SLICA) found that Arctic Alaska residents were more satisfied with their ability to control their own use of land and sea than other regions, but again Canada was not included [78]. Our results contradict the argument that more control and more involvement should relate to higher trust levels $[7,33]$. The NLCA in Nunavut retains Indigenous ownership and incorporates traditional knowledge in fish and wildlife management, more so than ANCSA in Alaska. Our interviews indicate that people in Alaska tended to assume that people representing the agencies, except from the oil and gas industries, were competent and some mentioned having the best interest of the community in mind. Between the 1970s and the late 1990s, trust in managers by Indigenous users rose [58], and our results indicate that trust in fish and wildlife management in these regions could potentially still be high.

Lastly, the isolation, culture, and the singularity of motivations for using resources (i.e., subsistence) might increase the likelihood of trust in Alaska and Nunavut. Less knowledge and interaction with external agencies could make some societies more likely to trust [79]. Isolation can help avoid negative interactions, which can be more influential in forming peoples' trust and perceptions $[59,80]$. The Inuit culture of sharing and acknowledging that caribou and mother nature are highly unpredictable [22] can also facilitate trust and decrease the tendency to associate actions 
or events with specific people or organizations. Given that these communities are remote and travel is expensive, there is minimal conflict with outside user groups [81]. Churchill, on the other hand, has been much less isolated but has had extensive experiences with large outside corporations and institutions, which has resulted in the formation of negative experiences and lower trust [36]. In addition, part of the economy of Churchill is related to polar bears and the arrival of polar bears for national and international tourism has proven to be controversial, bringing different motivations for using resources $[82,83]$.

\subsection{Limitations of our Study}

In our study it was not feasible to sample communities and respondents representatively. We used paired contrasts to select communities that were based in the Arctic, half of which have nearby natural resource extraction activities or infrastructure associated with such activities that was paired with a more subsistence-oriented community. Within communities, we also sampled participants to ensure sufficient variation in individual-level socioeconomic characteristics. By including multiple communities from different governance and cultural contexts in our study, we could suggest certain organizational-level characteristics that are relevant for trust assessment in the Arctic, and in other remote and Indigenous communities. However, the trust relationships identified here need to be further confirmed. Furthermore, the local context must always be considered when assessing trust in organizations, as evident in the case of Churchill.

Another limitation is the possibility to include quantitative instruments that capture different forms of trust relevant for community/agency relationships, such as those identified by Stern and Coleman [26], namely dispositional trust, rational trust, affinitive trust, and procedural trust. Institutional trust is also important in cross-national surveys, as trust between management agencies and communities is embedded in formal political and legal institutions that influence trust relationships at the local level [84]. Few have analyzed the relationships between these different forms of trust, but a recent study by PytlikZillig, Hamm, Shockley, Herian, Neal, Kimbrough, Tomkins and Bornstein [25] empirically investigated the relationships between different kinds of trust constructs and found that there are hardly any differences in trust when specific targets (such as trust in natural resource management organizations) were assessed. In our case, our questions had to be simple, as both language and cultural interpretations could influence the way trust was being assessed. We rather asked about trust with regard to specific organizations that were assessed relative to each other. We then followed up with open-ended questions, so the participants could explain their trust assessments. The resulting data did not allow us to fully analyze the characteristics that previously have been defined as important for trustworthiness (i.e., ability, benevolence, integrity and shared values), but we identified some characteristics that are particularly relevant for remote Indigenous communities, such as familiarity and direct communication with management agencies.

\section{Conclusions}

Sustainable management of fish, wildlife, and land in remote areas such as the Arctic could benefit from a higher degree of trust and communication between local resource users and management agencies. To better understand rural governance and its potential for facilitating or hindering sustainable resource management, we examined how organizational and individual characteristics relate to trust in resource management in different governance contexts. We identified some organizational-level characteristics that are relevant for building or maintaining trust, including the need for direct contact and communication with local managers or involvement of informal organizations that represents local norms and values in governance.

In our case, trust in management agencies and organizations was assessed according to the relevant knowledge, skills, and competencies that the organizations possessed or that which became evident through feedback and two-way communication with the residents. Management of fish-and-wildlife by use of scientific expertise was not considered relevant for some of the resource 
users, as they confer to local norms, values, and knowledge for decisions on fish-and-wildlife populations. Familiarity is also a key condition for trust in remote Indigenous communities, as their assessment may not be based on direct experience with agencies and organizations, but evaluated by the image they have of the authorities.

Our results have implications for the design of natural resource management, wherein local and informal organizations, and direct contact and communication with the resource users is beneficial for building trust between resource users and management agencies. Education also plays an important role and engaging fish and wildlife users in management and scientific inquiry at a young age can foster interest in learning. If structured appropriately, education can also improve transparency, increase communication about activities, and improve trust [73]. Given that communication and contact are so important, future research could focus on what methods of communication are most important, what information is most beneficial, and how organizations can help maintain a "local" presence in remote areas when governments are facing financial cutbacks.

Lastly, and perhaps needless to say, the trust relationships identified in this paper are not universal, and there will always be deviations from the general patterns, depending on local contexts such as in the case of lower trust levels in local organizations in Churchill, and the general high trust in remote communities that do not have many interactions with management agencies. We therefore advise that the three elements included here are analyzed empirically in a concerted action.

Supplementary Materials: The following are available online at http:/ /www.mdpi.com/2071-1050/10/9/3124/ s1, Table S1: Survey instrument used during interviews in 8 communities in Arctic Alaska $(n=64)$ and Canada (Churchill $n=17$ and Nunavut $n=50$ ) in 2013; Table S2: Characteristics of organizations used in our research with the number of interviewee responses $(n=131)$; Table S3: Characteristics of interviewees from interviews conducted in Alaska and Canada (Churchill and Nunavut) in 2013.

Author Contributions: Conceptualization, J.I.S., D.C. and V.H.; Data curation, J.I.S., N.L. and J.L.; Formal analysis, J.I.S.; Funding acquisition, J.I.S., V.H.; Writing—original draft, J.I.S.; Writing-review \& editing, D.C., N.L., J.L. and V.H.

Funding: The research presented was financed by TUNDRA (The Norwegian Research Council, (\#S192040/S30), the Belmont Forum project CONNECT (www.arcticsustainability.com, award number-1534006), and the Institute of Social and Economic Research at the University of Alaska Anchorage.

Conflicts of Interest: The authors declare no conflict of interest.

\section{References}

1. Bastian, C.T.; Keske, C.M.H.; McLeod, D.M.; Hoag, D.L. Landowner and land trust agent preferences for conservation easements: Implications for sustainable land uses and landscapes. Landsc. Urban Plan. 2017, 157, 1-13. [CrossRef]

2. Brain, R.G.; Hostetler, M.E.; Irani, T.A. Why do cattle ranchers participate in conservation easement agreements? Key motivators in decision making. Agroecol. Sustain. Food Syst. 2014, 38, 299-316. [CrossRef]

3. Hartel, T.; Fischer, J.; Cympeanu, C.; Milcu, A.I.; Hanspach, J.; Fazey, I. The importance of ecosystem services for rural inhabitants in a changing cultural landscape in Romania. Ecol. Soc. 2014, 19, 42. [CrossRef]

4. Stern, M.J. The power of trust: Toward a theory of local opposition to neighboring protected areas. Soc. Nat. Resour. 2008, 21, 859-875. [CrossRef]

5. Tomlinson, E.C.; Dineen, B.R.; Lewicki, R.J. Trust congruence among integrative negotiators as a predictor of joint-behavioral outcomes. Int. J. Confl. Manag. 2009, 20, 173-187. [CrossRef]

6. Cvetkovich, G.; Winter, P.L. Trust and social representations of the management of threatened and endangered species. Environ. Behav. 2003, 35, 286-307. [CrossRef]

7. Vaske, J.J.; Absher, J.D.; Bright, A.D. Salient value similarity, social trust and attitudes toward wildland fire management strategies. Hum. Ecol. Rev. 2007, 14, 223-232.

8. Lachapelle, P.R.; McCool, S.F. The role of trust in community wildland fire protection planning. Soc. Nat. Resour. 2012, 25, 321-335. [CrossRef]

9. Dirks, K.T. The effects of interpersonal trust on work group performance. J. Appl. Psychol. 1999, 84, 445-455. [CrossRef] [PubMed] 
10. Fisher, M.R. Estimating the effect of nonresponse bias on angler surveys. Trans. Am. Fish. Soc. 1996, 125, 118-126. [CrossRef]

11. Margerum, R. Beyond Consensus: Improving Collaborative Planning and Management; Massachusetts Institute of Technology: Boston, MA, USA, 2011.

12. Idrissou, L.; van Paassen, A.; Aarts, N.; Vodouhe, S.; Leeuwis, C. Trust and hidden conflict in participatory natural resources management: The case of the Pendjari National Park (PNP) in Benin. For. Policy Econ. 2013, 27, 65-74. [CrossRef]

13. Graham, S. A new perspective on the trust power nexus from rural Australia. J. Rural Stud. 2014, 36, 87-98. [CrossRef]

14. Stern, M.J.; Baird, T.D. Trust ecology and the resilience of natural resource management institutions. Ecol. Soc. 2015, 20, 11. [CrossRef]

15. Olsson, P.; Folke, C.; Berkes, F. Adaptive comanagement for building resilience in social-ecological systems. Environ. Manag. 2004, 34, 75-90. [CrossRef] [PubMed]

16. Schroeder, S.A.; Fulton, D.C.; Lawrence, J.S.; Cordts, S.D. How hunter perceptions of wildlife regulations, agency trust, and satisfaction affect attitudes about duck bag limits. Hum. Dimens. Wildl. 2017, 22, 454-475. [CrossRef]

17. Sabel, C.F. Studied trust -building new froms of cooperation in a volatile economy. Hum. Relat. 1993, 46, 1133-1170. [CrossRef]

18. Rousseau, D.M.; Sitkin, S.B.; Burt, R.S.; Camerer, C. Not so different after all: A cross-discipline view of trust. Acad. Manag. Rev. 1998, 23, 393-404. [CrossRef]

19. Ashley, C.; Carney, D. Sustainable Livelihoods: Lessons from Early Experience; Department for International Development: London, UK, 1999.

20. Meek, C.L.; Lovecraft, A.L.; Robards, M.D.; Kofinas, G.P. Building resilience through interlocal relations: Case studies of polar bear and walrus management in the bering strait. Mar. Policy 2008, 32, 1080-1089. [CrossRef]

21. Meyer, S.B.; Ward, P.R.; Jiwa, M. Does prognosis and socioeconomic status impact on trust in physicians? Interviews with patients with coronary disease in South Australia. BMJ Open 2012, 2, e001389. [CrossRef] [PubMed]

22. Burch, E.S. Social Life in Northwest Alaska: The Structure of Inupiaq Eskimo Nations; University of Alaska Press: Fairbanks, AK, USA, 2006; p. xiv. 478p.

23. Sharp, E.A.; Thwaites, R.; Curtis, A.; Millar, J. Trust and trustworthiness: Conceptual distinctions and their implications for natural resources management. J. Environ. Plan. Manag. 2013, 56, 1246-1265. [CrossRef]

24. Mayer, R.C.; Davis, J.H.; Schoorman, F.D. An integrative model of organizational trust. Acad. Manag. Rev. 1995, 20, 709-734. [CrossRef]

25. PytlikZillig, L.M.; Hamm, J.A.; Shockley, E.; Herian, M.N.; Neal, T.M.S.; Kimbrough, C.D.; Tomkins, A.J.; Bornstein, B.H. The dimensionality of trust-relevant constructs in four institutional domains: Results from confirmatory factor analyses. J. Trust Res. 2016, 6, 111-150. [CrossRef]

26. Stern, M.J.; Coleman, K.J. The multidimensionality of trust: Applications in collaborative natural resource management. Soc. Nat. Resour. 2015, 28, 117-132. [CrossRef]

27. Fitzgerald, J.; Wolak, J. The roots of trust in local government in Western Europe. Int. Polit. Sci. Rev. 2014, 37, 130-146. [CrossRef]

28. Easton, D. Reassessment of concept of political support. Br. J. Polit. Sci. 1975, 5, 435-457. [CrossRef]

29. Wald, D.M.; Nelson, K.A.; Gawel, A.M.; Rogers, H.S. The role of trust in public attitudes toward invasive species management on guam: A case study. J. Environ. Manag. 2018. [CrossRef] [PubMed]

30. Broderstad, E.G.; Hausner, V.; Josefsen, E.; Søreng, S.U. Being the master in one's own house: Support to the new arctic land management arrangement in Finnmark, Norway. J. Rural Stud. 2018, submitted.

31. Nunn, N. Culture and the historical process. Econ. Hist. Dev. Reg. 2012, 27, S108-S126.

32. Heemskerk, M.; Duijves, C.; Pinas, M. Interpersonal and institutional distrust as disabling factors in natural resources management: Small-scale gold miners and the government in Suriname. Soc. Nat. Resour. 2015, 28, 133-148. [CrossRef]

33. Scholtz, C.S. Negotiating Claims: The Emergence of Indigenous Land Claim Negotiation Policies in Australia, Canada, New Zealand, and the United States; Routledge: New York, NY, USA, 2006; p. viii, 259p.

34. Canby, W.C. American Indian Law in a Nutshell, 5th ed.; West: St. Paul, MN, USA, 2009; p. 1vii, 548p. 
35. Steel, J.L. Interpersonal correlates of trust and self-disclosure. Psychol. Rep. 1991, 68, 1319-1320. [CrossRef]

36. Lankshear, J. Challenged by Corporations: Local Perceptions on Land Use and Natural Resource Management in Churchill, Manitoba; University of Saskatchewan: Saskatoon, SK, Canada, 2013.

37. Wenzel, G.W. The Social Economy of Sharing: Resource Allocation and Modern Hunter-Gatherers; National Museum of Ethnology: Osaka, Japan, 2000; p. II, 219p.

38. Morselli, D.; Spini, D.; Devos, T. Trust in institutions and human values in the european context: A comparison between the world value survey and the european social survey. Psicol. Soc. 2015, 10, $209-222$.

39. Jen, M.H.; Sund, E.R.; Johnston, R.; Jones, K. Trustful societies, trustful individuals, and health: An analysis of self-rated health and social trust using the world value survey. Health Place 2010, 16, 1022-1029. [CrossRef] [PubMed]

40. Smith, J.W.; Leahy, J.E.; Anderson, D.H.; Davenport, M.A. Community/agency trust and public involvement in resource planning. Soc. Nat. Resour. 2013, 26, 452-471. [CrossRef]

41. Hardin, R. Trust and Trustworthiness; Russell Sage Foundation: New York, NY, USA, 2002; p. xxi, 234 p.

42. Absher, J.D.; Vaske, J.J. The role of trust in residents' fire wise actions. Int. J. Wildland Fire 2011, 20, 318-325. [CrossRef]

43. Kendrick, A. The flux of trust: Caribou co-management in Northern Canada. Environments 2003, 31, 43-60.

44. Frels, R.K.; Onwuegbuzie, A.J. Administering quantitative instruments with qualitative interviews: A mixed research approach. J. Couns. Dev. 2013, 91, 184-194. [CrossRef]

45. AKDCCED. Community Database Online. Available online: https://www.commerce.alaska.gov/dcra/ DCRAExternal (accessed on 2 June 2018).

46. AKDLWD. Alaska Labor and Workforce Development. Available online: http://labor.alaska.gov/ (accessed on 30 August 2018).

47. Shanks, A. Northwest Arctic Borough: A Look at an Economy in the Remote North; Alaska Department of Labor \& Workforce Development: Juneau, AK, USA, 2009.

48. Statistics Canada. Census of Canada. Available online: https://www12.statcan.gc.ca/census-recensement/ index-eng.cfm (accessed on 30 August 2018).

49. Southcott, C. Northern Communities Working Together. The Social Economy of Canada's North; University of Totonto Press: Toronto, ON, Canada, 2015.

50. Caine, K.J.; Davison, C.M.; Stewart, E.J. Preliminary field-work: Methodological reflections from Northern Canadian research. Qual. Res. 2009, 9, 489-513. [CrossRef]

51. Dunn, J.R.; Schweitzer, M.E. Feeling and believing: The influence of emotion on trust. J. Personal. Soc. Psychol. 2005, 88, 736-748. [CrossRef] [PubMed]

52. Agresti, A. Analysis of Ordinal Categorical Data, 2nd ed.; Wiley: Hoboken, NJ, USA, 2010; p. xi. 396p.

53. Institute, S. The Sas System for Windows; Release 9.4; Sas Inst.: Cary, NC, USA, 2012.

54. Harrell, F.E. Regression Modeling Strategies: With Applications to Linear Models, Logistic Regression, and Survival Analysis; Springer: New York, NY, USA, 2001; p. xxii. 568p.

55. StataCorp. Stata Statistical Software; Release 15; StataCorp LLC: College Station, TX, USA, 2017.

56. Hedeker, D.; Gibbons, R.D. A random-effects ordinal regression-model for multilevel analysis. Biometrics 1994, 50, 933-944. [CrossRef] [PubMed]

57. Schmidt-Catran, A.W.; Fairbrother, M. The random effects in multilevel models: Getting them wrong and getting them right. Eur. Sociol. Rev. 2016, 32, 23-38. [CrossRef]

58. Kruse, J.; Klein, D.R.; Braund, S.R.; Moorehead, L.; Simeone, B. Co-management of natural resources: Comparison of two caribou management systems. Hum. Organ. 1998, 54, 447-458. [CrossRef]

59. Gray, S.; Shwom, R.; Jordan, R. Understanding factors that influence stakeholder trust of natural resource science and institutions. Environ. Manag. 2012, 49, 663-674. [CrossRef] [PubMed]

60. La Porta, R.; Lopez-De-Silanes, F.; Shleifer, A.; Vishny, R.W. Trust in large organizations. EAE Pap. Proc. 1997, 87, 333-338.

61. Clark, D.; Slocombe, S. Adaptive co-management and grizzly bear-human conflicts in two Northern Canadian aboriginal communities. Hum. Ecol. 2011, 39, 627-640. [CrossRef]

62. Kofinas, G.P.; Herman, S.J.; Meek, C. Novel problems require novel solutions: Innovation as an outcome of adaptive co-management. In Adaptive Co-Management: Collaboration, Learning, and Multi-Level Governance; Armitage, D., Berkes, F., Doubleday, N., Eds.; University of British Columbia Press: Vancouver, BC, Canada, 2007; pp. 249-267. 
63. Barber, B. The Logic and Limits of Trust; Rutgers University Press: New Brunswick, NJ, Canada, 1983.

64. Pomeroy, R.S.; McConney, P.; Mahon, R. Comparative analysis of coastal resource co-management in the caribbean. Ocean Coast. Manag. 2004, 47, 429-447. [CrossRef]

65. Usseglio, P.; Schuhbauer, A.; Friedlander, A. Collaborative approach to fisheries management as a way to increase the effectiveness of future regulations in the galapagos archipelago. In The Galapagos Marine Reserve: A Dynamic Social-Ecological System; Denkinger, J., Vinueza, L., Eds.; Springer International Publishing: Cham, Switzerland, 2014; pp. 187-202.

66. Bunnefeld, N.; Nicholson, E.; Milner-Gulland, E.J. Decision-Making in Conservation and Natural Resource Management: Models for Interdisciplinary Approaches; Cambridge University Press: Cambridge, UK, 2017; p. xii, 275p.

67. Fauchald, P.; Hausner, V.H.; Schmidt, J.I.; Clark, D.A. Transitions of social-ecological subsistence systems in the arctic. Int. J. Commons 2017, 11, 275-329. [CrossRef]

68. Hooghe, M.; Marien, S.; de Vroome, T. The cognitive basis of trust. The relation between education, cognitive ability, and generalized and political trust. Intelligence 2012, 40, 604-613. [CrossRef]

69. Bacharach, M.; Gambetta, D. Trust in signs. In Trust in Society; Cook, K.S., Ed.; Russell Sage Foundation: New York, NY, USA, 2001; pp. 148-184.

70. Nannestad, P. What have we learned about generalized trust, if anything? Annu. Rev. Political Sci. 2008, 11, 413-436. [CrossRef]

71. Van Maele, D.; Van Houtte, M. Collegial trust and the organizational context of the teacher workplace: The role of a homogeneous teachability culture. Am. J. Educ. 2011, 117, 437-464. [CrossRef]

72. Deary, I.J.; Batty, G.D.; Gale, C.R. Bright children become enlightened adults. Psychol. Sci. 2008, 19, 1-6. [CrossRef] [PubMed]

73. Ardoin, N.M.; DiGiano, M.L.; O'Connor, K.; Podkul, T.E. The development of trust in residential environmental education programs. Environ. Educ. Res. 2017, 23, 1335-1355. [CrossRef]

74. Delhey, J.; Newton, K. Who trusts? The origins of social trust in seven societies. Eur. Soc. 2003, 5, 93-137. [CrossRef]

75. Ziersch, A.; Putland, C.; Palmer, C.; MacDougall, C.; Baum, F. Neighbourhood life, social capital and perceptions of safety in the western suburbs of adelaide. Aust. J. Soc. Issues 2007, 42, 549-562. [CrossRef]

76. Stewart, E.J.; Jacobson, D.; Draper, D. Public participation geographic information systems (ppgis): Challenges of implementation in churchill, manitoba. Can. Geogr. 2008, 52, 351-366. [CrossRef]

77. AJIC. Treaty land entitlement and the northern flood agreement. In Aboriginal Justice Implementation Commission Final Report; Aboriginal Justice Implementation Commission: Manitoba, Canada, 2001.

78. Andersen, T.; Kruse, J.; Poppel, B. Survey of living conditions in the arctic: Inuit, saami and the Indigenous peoples of chukotka (slica). Arctic 2002, 55, 310-315. [CrossRef]

79. Ward, P.R.; Mamerow, L.; Meyer, S.B. Interpersonal trust across six asia-pacific countries: Testing and extending the 'high trust society' and 'low trust society' theory. PLoS ONE 2014, 9, e95555. [CrossRef] [PubMed]

80. Slovic, P. Perceived risk, trust, and democracy. Risk Anal. 1993, 13, 675-682. [CrossRef]

81. Clark, D.A.; Lee, D.S.; Freeman, M.M.R.; Clark, S.G. Polar bear conservation in Canada: Defining the policy problems. Arctic 2008, 61, 347-360. [CrossRef]

82. Lemelin, R.H.; Fennell, D.; Smale, B. Polar bear viewers as deep ecotourists: How specialised are they? J. Sustain. Tour. 2008, 16, 42-62. [CrossRef]

83. Lemelin, H.; Dawson, J.; Stewart, E.J.; Maher, P.; Lueck, M. Last-chance tourism: The boom, doom, and gloom of visiting vanishing destinations. Curr. Issues Tour. 2010, 13, 477-493. [CrossRef]

84. Rothstein, B.; Stolle, D. The state and social capital-An institutional theory of generalized trust. Comp. Polit. 2008, 40, 441-459. [CrossRef]

(C) 2018 by the authors. Licensee MDPI, Basel, Switzerland. This article is an open access article distributed under the terms and conditions of the Creative Commons Attribution (CC BY) license (http:/ / creativecommons.org/licenses/by/4.0/). 